Provided for non-commercial research and education use. Not for reproduction, distribution or commercial use.

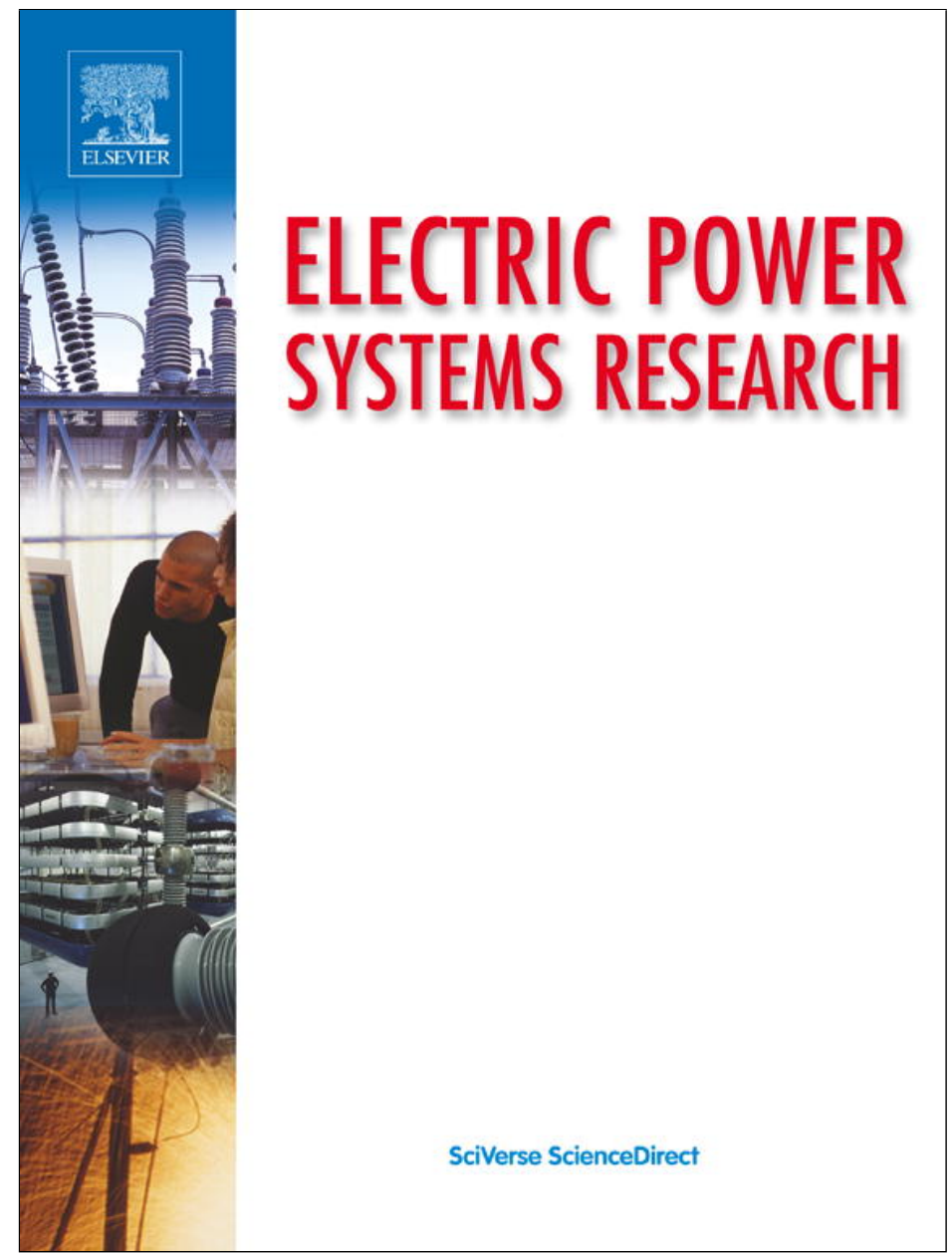

This article appeared in a journal published by Elsevier. The attached copy is furnished to the author for internal non-commercial research and education use, including for instruction at the authors institution and sharing with colleagues.

Other uses, including reproduction and distribution, or selling or licensing copies, or posting to personal, institutional or third party websites are prohibited.

In most cases authors are permitted to post their version of the article (e.g. in Word or Tex form) to their personal website or institutional repository. Authors requiring further information regarding Elsevier's archiving and manuscript policies are encouraged to visit:

http://www.elsevier.com/authorsrights 


\title{
Hybrid power filter for advanced power quality in industrial systems
}

\author{
Jan Švec ${ }^{\mathrm{a}, *}$, Zdeněk Müller ${ }^{\mathrm{a}}$, Andrew Kasembe ${ }^{\mathrm{a}}$, Josef Tlustý ${ }^{\mathrm{a}}$, Viktor Valouch ${ }^{\mathrm{b}}$ \\ a Department of Electrical Power Engineering, Faculty of Electrical Engineering, CTU in Prague, Technická 2, 16627 Prague 6, Czech Republic \\ ${ }^{\mathrm{b}}$ Department of Electric Machines, Drives and Power Electronics, Institute of Thermomechanics, Academy of Sciences of the Czech Republic, Dolejškova 5, \\ 18202 Prague 8, Czech Republic
}

\section{A R T I C L E I N F O}

Article history:

Received 15 December 2011

Received in revised form 20 April 2013

Accepted 21 May 2013

\section{Keywords:}

Hybrid power filter

Control strategy

Industrial system

Harmonics

Simulation

Measurement

\begin{abstract}
A B S T R A C T
The paper presents the structure and control strategy of the hybrid power filter (HPF) with a split passive part. Its impedance is divided into two parts tuned to $50 \mathrm{~Hz}$ and $250 \mathrm{~Hz}$.

The HPF topology is very efficient to mitigate harmonic currents. The fundamental frequency voltage at the converter terminals is remarkably small in comparison with the grid voltage at the same moment. The HPF functionality is only negligibly influenced by the grid inductance changes.

The HPF characteristics were compared with those for standard HPF topologies and the classical passive compensation by means of simulations done in the Matlab/Simulink environment. The voltage and current responses and their harmonic spectra were also measured in an industrial plant under different conditions.
\end{abstract}

() 2013 Elsevier B.V. All rights reserved.

\section{Introduction}

Passive filters (PF) have been intended preferably for the compensation of the load-lagging power factor and/or its selected current harmonics. However, their frequency characteristics are unfavorably influenced by a variable grid impedance and thus the danger of resonance excitation exists. Active power filters (APFs) represent a perspective solution to improve the power quality in transmission and distribution grids [1-3]. Contrary to that of PFs, the function of active filters is substantially influenced neither by aging nor by changes in the grid impedance. Nevertheless, the APF's higher price is, aside from difficulties if an APF is used in highvoltage applications, the main obstacle for their broad utilization. Especially for high power, the use of self-contained APFs is not recommended due to the problems related to appropriate control strategies, higher prices and the lower efficiency of APFs in comparison to those of PFs.

Thus, combined systems of the passive and active filters are more promising in many areas [4-12]. We call such a configuration a hybrid power filter (HPF). The active part of such a hybrid filter and its control strategy may be designed to fulfill different main tasks, such as the compensation of voltage and/or current harmonics and/or lagging power factor of unsymmetrical loads or the

\footnotetext{
* Corresponding author. Tel.: +420 224352 372; fax: +420 233337556. E-mail addresses: jan.svec@fel.cvut.cz (J. Švec), zdenek.muller@fel.cvut.cz (Z. Müller), kasemand@fel.cvut.cz (A. Kasembe), tlusty@fel.cvut.cz (J. Tlustý), valouch@it.cas.cz (V. Valouch).
}

contribution to the grid stabilization [13-16]. The trade off between the required goals of the PF and the APF serves to highlight the major benefits of the HPF. The active filters, either self-contained or as parts of HPFs, may be connected in parallel or in series with nonlinear loads [17]. The parallel (shunt) APFs inject current harmonics with the same magnitude and the reverse phase in comparison with those of the load current harmonics into the point of the load coupling [18-24], whereas the series APFs represent rather harmonic insulators connected between the grid and a nonlinear load [25].

We can distinguish a few main hybrid filter configurations according to the connection of active filters to their passive counterparts. The hybrid filters main performance criteria are [26-28]:

- Frequency characteristics of the grid-hybrid filter-load system reflecting the system tendency to fall into a resonance and showing the voltage and/or current harmonics diminishing potential.

- Total harmonic distortions of the grid current and load voltage for the hybrid filter in function.

- Designed filter control strategies stability in case of the disturbances in the supply grid and/or load.

- Hybrid filters demanded rated voltages, currents and powers [29-31].

Among a few efficient HPF topologies, the system with the series connection of a passive $L-C$ resonant circuit and the APF has been accepted as a good solution [5,7], especially for medium voltage systems. For example, a $3.3 \mathrm{kV}$ transformerless AC/DC power conversion system is presented in [32], based on the HPF topology with a passive $L-C$ resonant circuit and a small APF series connection. The 
system consists of a three-phase diode rectifier and a parallel HPF. The APF is based on a voltage-sourced PWM inverter. The APF rating is much smaller than that of a stand-alone parallel APF. Nevertheless, the capability to filter the load current harmonics decreases gradually for frequencies higher than the resonant frequency (frequencies) of the HPF passive part. In addition, the magnitude of the current generated by the converter is not much lower than the load current magnitude, especially for the lowest orders harmonics. Thus, a question arises whether this HPF topology proper modification could improve the indices mentioned above and how such a modification can influence other important performance criteria. A possible solution is discussed in this paper.

The paper is focused on a new HPF topology and control strategy. This HPF includes a split passive part whose impedance is divided into two individual parts tuned to $50 \mathrm{~Hz}$ and $250 \mathrm{~Hz}$ [33]. The research objectives can be stated as follows:

- To analyze a new HPF topology and control strategy in terms of its effectiveness to mitigate harmonics and demands placed on the HPF active part.

- To develop an industrial system model in the Matlab/Simulink environment on the basis of real data measured and collected in such an existing system.

- To analyze the system for different classic options of harmonic current filtration and reactive power compensation in the frequency as well as the time domain.

- To implement the HPF topology and control strategy into the industrial system model and to prove its functionality and effectiveness in comparison to the simpler topology with a passive $L-C$ resonant circuit and the APF series connection.

\section{HPF topology and equivalent diagram}

The basic principle of the new HPF parallel connection to a nonlinear load is shown in Fig. 1. The HPF is characterized by a split passive part whose impedance is divided into two individual parts tuned to $50 \mathrm{~Hz}\left(C_{0}, L_{0}\right)$ and $250 \mathrm{~Hz}\left(C_{1}, C_{0}, L_{0}\right)$. The parallel $\mathrm{PF}$ is connected to the same PCC (point of common coupling) as well.

The usual HPF feed-forward control is used. The measured fundamental harmonic grid current RMS value is calculated, multiplied by a harmonic signal with the grid frequency (produced by a PLL circuit) and subtracted from the original current. Thus we obtain the harmonic current $i_{\mathrm{AF}}=-K \cdot i_{\mathrm{S}}$ which should be generated by the HPF to compensate the harmonic load current ( $K$ is the feedback gain).

The single-phase proposed HPF equivalent diagram is depicted in Fig. 2. On the basis of this circuit, we can find transfer functions as well as frequency characteristics for input variables $u_{\mathrm{S}}$ and $i_{\mathrm{L}}$ and output variables $i_{S}$ and $u_{\mathrm{L}}$. The frequency characteristics of some simple topologies may be deduced by the proper choice of individual branch impedances in Fig. 2. For example, the conventional topology with a passive $L-C$ resonant circuit and the APF series connection, as mentioned before, may be obtained by setting $Z_{0} \rightarrow \infty$.

The single-phase equivalent diagram of the proposed HPF connected to the non-linear load presented in Fig. 2 can be described by the following circuit equations:

$u_{\mathrm{L}}=Z_{1} i_{\mathrm{FAF}}+Z_{0} i_{0}=Z_{1} i_{\mathrm{FAF}}+Z_{0}\left(i_{\mathrm{FAF}}-i_{\mathrm{AF}}\right)=\left(Z_{1}+Z_{0}\right) i_{\mathrm{FAF}}-Z_{0} i_{\mathrm{AF}}$

$u_{\mathrm{L}}=Z_{\mathrm{PF}} i_{\mathrm{PF}}$

$i_{\mathrm{S}}=i_{\mathrm{L}}+i_{\mathrm{PF}}+i_{\mathrm{FAF}}$

$u_{\mathrm{S}}=Z_{\mathrm{S}} i_{\mathrm{S}}+u_{\mathrm{L}}$

where

$Z_{\mathrm{S}}, Z_{\mathrm{PF}}, Z_{0}$ and $Z_{1}$ are the impedances of the grid, PF and two APF parts, respectively.

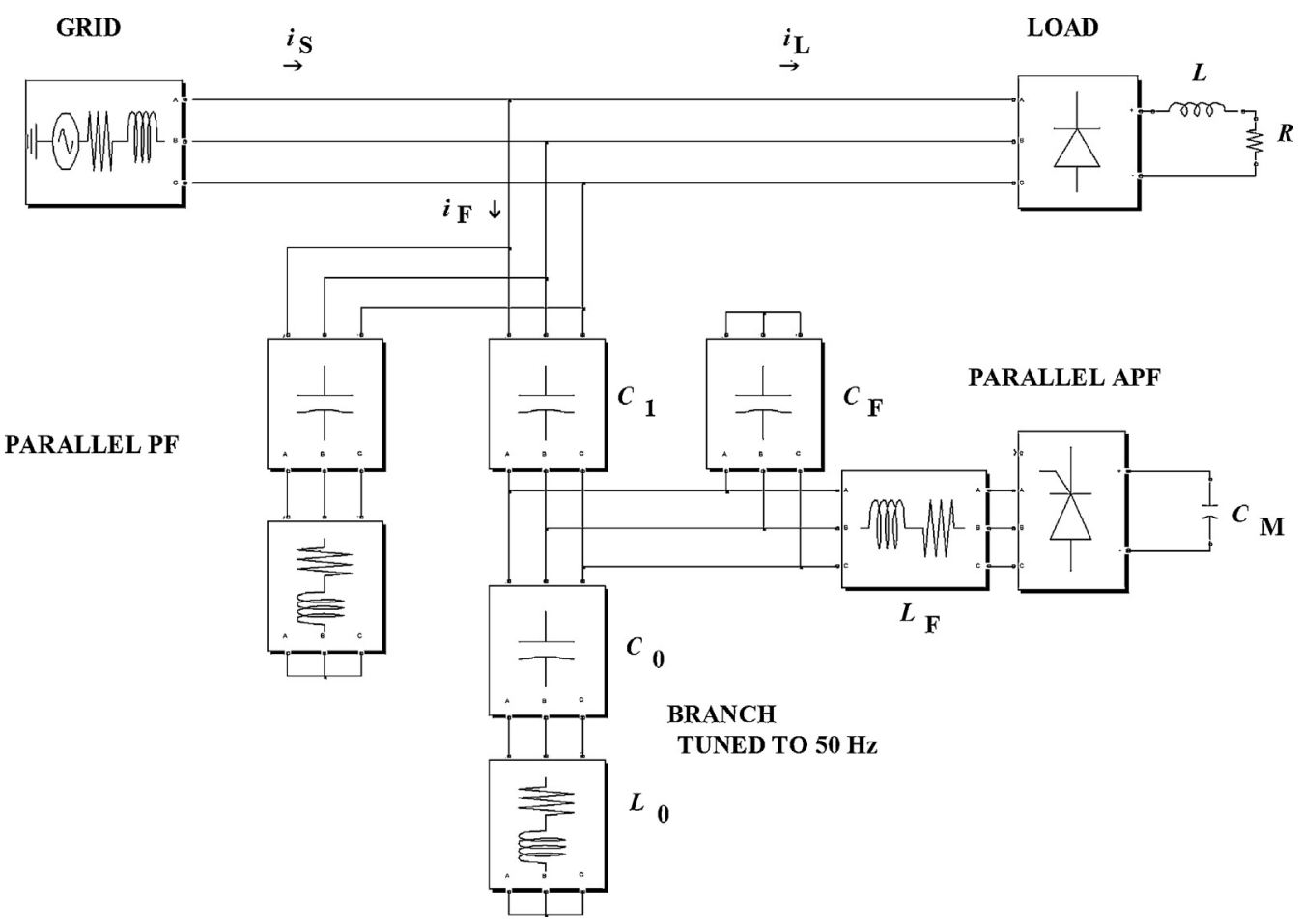

Fig. 1. HPF diagram with two individual passive parts tuned to $50 \mathrm{~Hz}\left(L_{0}, C_{0}\right)$ and $250 \mathrm{~Hz}\left(C_{1}, L_{0}, C_{0}\right)$ connected to the grid together with classic parallel PF. 


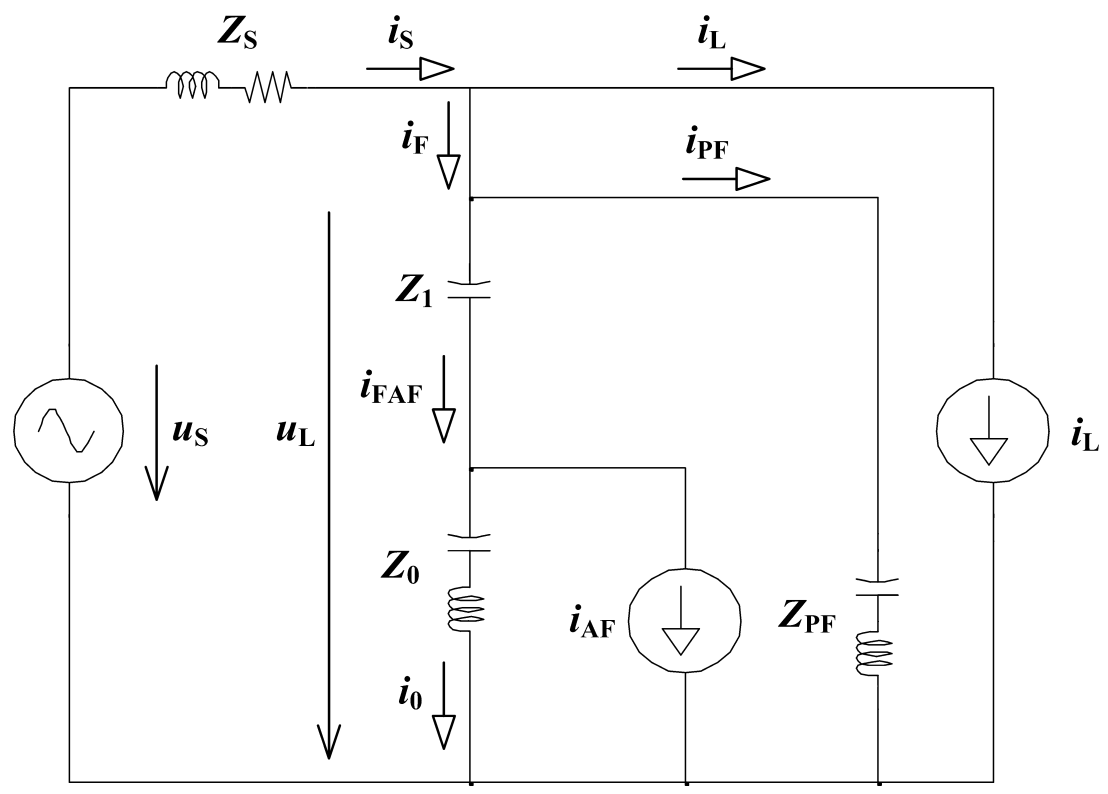

Fig. 2. Single phase equivalent diagram of the proposed HPF connected to a non-linear load.

$u_{\mathrm{S}}$ and $i_{\mathrm{L}}$ are the system input variables that depend on the grid and load behavior.

$i_{\mathrm{AF}}$ is the current generated by the converter (it is deduced from the grid current for the feedback control).

$i_{\mathrm{PF}}, i_{\mathrm{FAF}}, i_{\mathrm{S}}$ and $u_{\mathrm{L}}$ are the system output variables influenced by the grid and HPF parameters.

By means of several manipulations, we can find the expressions for the output variables (5)-(8). If the impedances are expressed in the frequency domain, we can find the frequency transfer functions between individual variables.

$i_{\mathrm{PF}}=\frac{\left(Z_{1}+Z_{0}\right)\left(i_{\mathrm{L}} Z_{\mathrm{S}}-u_{\mathrm{S}}\right)+Z_{1} i_{\mathrm{AF}} Z_{\mathrm{S}}}{-Z_{\mathrm{PF}} Z_{\mathrm{S}}-\left(Z_{1}+Z_{0}\right)\left(Z_{\mathrm{S}}+Z_{\mathrm{PF}}\right)}$

$i_{\mathrm{FAF}}=\frac{Z_{\mathrm{PF}}\left(i_{\mathrm{L}} Z_{\mathrm{S}}-u_{\mathrm{S}}\right)-Z_{0} i_{\mathrm{AF}}\left(Z_{\mathrm{S}}+Z_{\mathrm{PF}}\right)}{-Z_{\mathrm{PF}} Z_{\mathrm{S}}-\left(Z_{1}+Z_{0}\right)\left(Z_{\mathrm{S}}+Z_{\mathrm{PF}}\right)}$

$i_{\mathrm{S}}=\frac{-Z_{\mathrm{PF}}\left(u_{\mathrm{S}}+Z_{0} i_{\mathrm{AF}}\right)-\left(Z_{1}+Z_{0}\right)\left(u_{\mathrm{S}}+Z_{\mathrm{PF}} i_{\mathrm{L}}\right)}{-Z_{\mathrm{PF}} Z_{\mathrm{S}}-\left(Z_{1}+Z_{0}\right)\left(Z_{\mathrm{S}}+Z_{\mathrm{PF}}\right)}$

$u_{\mathrm{L}}=Z_{\mathrm{PF}} i_{\mathrm{PF}}=Z_{\mathrm{PF}} \frac{\left(Z_{1}+Z_{0}\right)\left(i_{\mathrm{L}} Z_{\mathrm{S}}-u_{\mathrm{S}}\right)+Z_{1} i_{\mathrm{AF}} Z_{\mathrm{S}}}{-Z_{\mathrm{PF}} Z_{\mathrm{S}}-\left(Z_{1}+Z_{0}\right)\left(Z_{\mathrm{S}}+Z_{\mathrm{PF}}\right)}$

If the feedback control algorithm is determined by the relation $i_{\mathrm{AF}}=-K \cdot i_{\mathrm{S}}$ where $K$ is the feedback gain, it is easy to formulate the frequency transfer functions between the input (error) variables $i_{\mathrm{L}}$ and $u_{\mathrm{S}}$ and the output (controlled) variables $i_{\mathrm{S}}$ and $u_{\mathrm{L}}$, respectively converter current and voltage $i_{\mathrm{AF}}$ and $u_{\mathrm{AF}}$.

$$
\begin{aligned}
i_{\mathrm{S}}= & \frac{\left(Z_{1}+Z_{0}+Z_{\mathrm{PF}}\right)}{Z_{\mathrm{PF}}\left(Z_{\mathrm{S}}+K Z_{0}\right)+\left(Z_{1}+Z_{0}\right)\left(Z_{\mathrm{S}}+Z_{\mathrm{PF}}\right)} u_{\mathrm{S}} \\
& +\frac{Z_{\mathrm{PF}}\left(Z_{1}+Z_{0}\right)}{Z_{\mathrm{PF}}\left(Z_{\mathrm{S}}+K Z_{0}\right)+\left(Z_{1}+Z_{0}\right)\left(Z_{\mathrm{S}}+Z_{\mathrm{PF}}\right)} i_{\mathrm{L}}=Y_{\mathrm{SS}} u_{\mathrm{S}}+F_{\mathrm{SL}} i_{\mathrm{L}} \\
u_{\mathrm{L}}= & \frac{Z_{\mathrm{PF}}\left[Z_{1}+Z_{0}(1+K)\right]}{Z_{\mathrm{PF}}\left(Z_{\mathrm{S}}+K Z_{0}\right)+\left(Z_{1}+Z_{0}\right)\left(Z_{\mathrm{S}}+Z_{\mathrm{PF}}\right)} u_{\mathrm{S}} \\
& +\frac{-Z_{\mathrm{PF}} Z_{\mathrm{S}}\left(Z_{1}+Z_{0}\right)}{Z_{\mathrm{PF}}\left(Z_{\mathrm{S}}+K Z_{0}\right)+\left(Z_{1}+Z_{0}\right)\left(Z_{\mathrm{S}}+Z_{\mathrm{PF}}\right)} i_{\mathrm{L}}=F_{\mathrm{LS}} u_{\mathrm{S}}+Z_{\mathrm{LL}} i_{\mathrm{L}}
\end{aligned}
$$

$i_{\mathrm{AF}}=-K i_{\mathrm{S}}=-K\left(Y_{\mathrm{SS}} u_{\mathrm{S}}+F_{\mathrm{SL}} i_{\mathrm{L}}\right)=Y_{\mathrm{AFS}} u_{\mathrm{S}}+F_{\mathrm{AFL}} i_{\mathrm{L}}$

$$
\begin{aligned}
u_{\mathrm{AF}}= & \frac{Z_{0}}{Z_{1}+Z_{0}} u_{\mathrm{L}}-\frac{Z_{1} Z_{0}}{Z_{1}+Z_{0}} i_{\mathrm{AF}}=\frac{Z_{0}}{Z_{1}+Z_{0}}\left(F_{\mathrm{LS}} u_{\mathrm{S}}+Z_{\mathrm{LL}} i_{\mathrm{L}}\right) \\
& +\frac{K Z_{1} Z_{0}}{Z_{1}+Z_{0}}\left(Y_{\mathrm{SS}} u_{\mathrm{S}}+F_{\mathrm{SL}} i_{\mathrm{L}}\right)=F_{\mathrm{AFS}} u_{\mathrm{S}}+Z_{\mathrm{AFL}} i_{\mathrm{L}}
\end{aligned}
$$

\section{Analysis in the frequency domain}

The magnitude-frequency characteristics presented below are the graphical interpretation of the frequency transfer functions (9)-(12) among the input harmonic current $i_{\mathrm{L}}$ and the grid voltage $u_{\mathrm{S}}$, and the output variables $i_{\mathrm{S}}, u_{\mathrm{L}}, i_{\mathrm{AF}}$ and $u_{\mathrm{AF}}$.

Thus

$F_{\mathrm{SL}}=i_{\mathrm{S}} / i_{\mathrm{L}}$ characterizes a measure of the load harmonic current $i_{\mathrm{L}}$ penetration into the grid current $i_{S}$.

$Y_{S S}=i_{S} / u_{S}$ characterizes a susceptibility to series resonances.

$Z_{\mathrm{LL}}=u_{L} / i_{\mathrm{L}}$ characterizes a susceptibility to parallel resonances.

$F_{\mathrm{LS}}=u_{\mathrm{L}} / u_{\mathrm{S}}$ characterizes a measure of the grid harmonic voltage $u_{\mathrm{S}}$ penetration into the load voltage $u_{\mathrm{L}}$.

$F_{\mathrm{AFL}}=i_{\mathrm{AF}} / i_{\mathrm{L}}$ characterizes the rate $i_{\mathrm{AF}} / i_{\mathrm{L}}$.

$Z_{\mathrm{AFL}}=u_{\mathrm{AF}} / i_{\mathrm{L}}$ characterizes the rate $u_{\mathrm{AF}} / i_{\mathrm{L}}$

It is clear that lower values of the indices $F_{\mathrm{SL}}, Z_{\mathrm{LL}}, Y_{\mathrm{SS}}$ and $F_{\mathrm{LS}}$ indicate a better filtration of harmonic load currents and grid voltages while lower values of $F_{\mathrm{AFL}}, Z_{\mathrm{AFL}}$ mean that lower currents and voltages have to be generated by the converter to suppress the harmonic load current $i_{\mathrm{L}}$.

The following Figs. 3-7 show the magnitude-frequency characteristics $F_{\mathrm{SL}}=i_{\mathrm{S}} / i_{\mathrm{L}}, Y_{\mathrm{SS}}=i_{\mathrm{S}} / u_{\mathrm{S}}, F_{\mathrm{LS}}=u_{\mathrm{L}} / u_{\mathrm{S}}$ and $F_{\mathrm{AFL}}=i_{\mathrm{AF}} / i_{\mathrm{L}}$ for the proposed HPF parameters declared in the Appendix A and $K=10$ (unless another value is mentioned). Some of these figures compare the characteristics valid for the proposed HPF with those for other topologies, especially the PF standing alone and the conventional topology with the series connection of a passive $L-C$ resonant circuit and the $\operatorname{APF}\left(Z_{0} \rightarrow \infty\right)$ as well.

Fig. 3 shows how the frequency characteristics $F_{\mathrm{SL}}=i_{\mathrm{S}} / i_{\mathrm{L}}$ are influenced by the changes of the grid inductance. The gain $K=0$ means that only the passive parts are in function. We can see that the characteristics depend extensively on the grid inductance value 


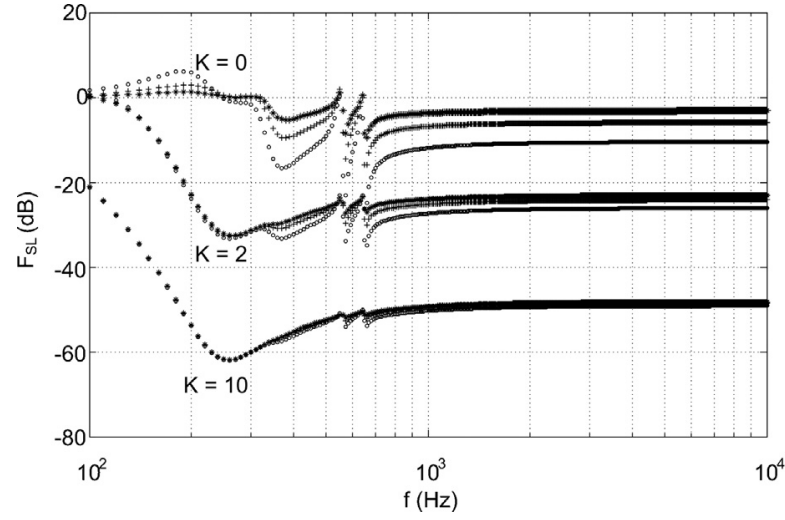

Fig. 3. $F_{\mathrm{SL}}=i_{\mathrm{S}} / i_{\mathrm{L}}$ for passive parts $(K=0)$ and for $\operatorname{HPF}(K=2,10)$ for different grid inductance values $L_{S}$.

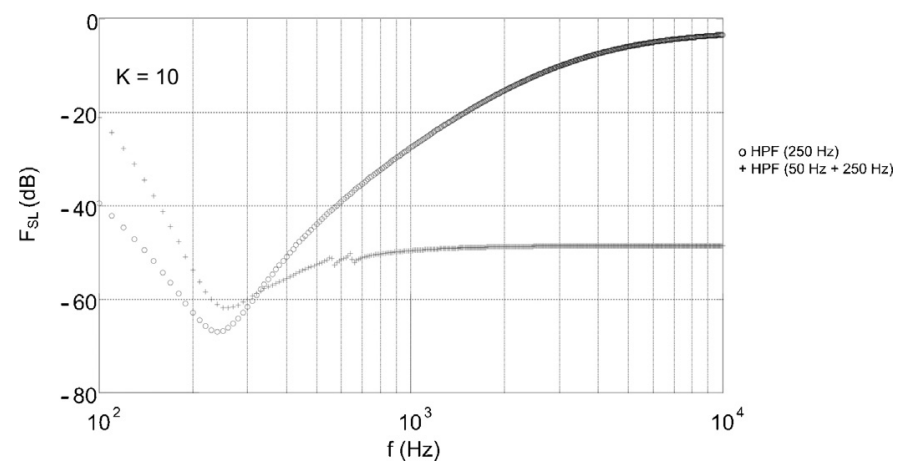

Fig.4. Comparison of $F_{\mathrm{SL}}=i_{\mathrm{S}} / i_{\mathrm{L}}$ for HPF with the series connection of only one passive $L-C$ resonant circuit $\left(250 \mathrm{~Hz}, Z_{0} \rightarrow \infty\right)$ to that for the proposed HPF with the split passive part as shown in Fig. 2.

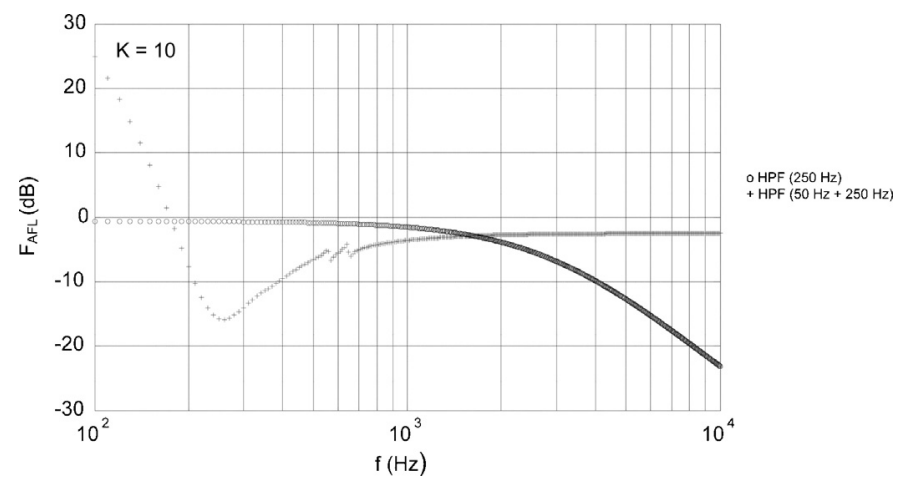

Fig. 5. Comparison of $F_{\mathrm{AFL}}=i_{\mathrm{AF}} / i_{\mathrm{L}}$ for HPF with the series connection of only one passive $L-C$ resonant circuit $\left(250 \mathrm{~Hz}, Z_{0} \rightarrow \infty\right)$ to that for the proposed HPF with the split passive part as shown in Fig. 2.

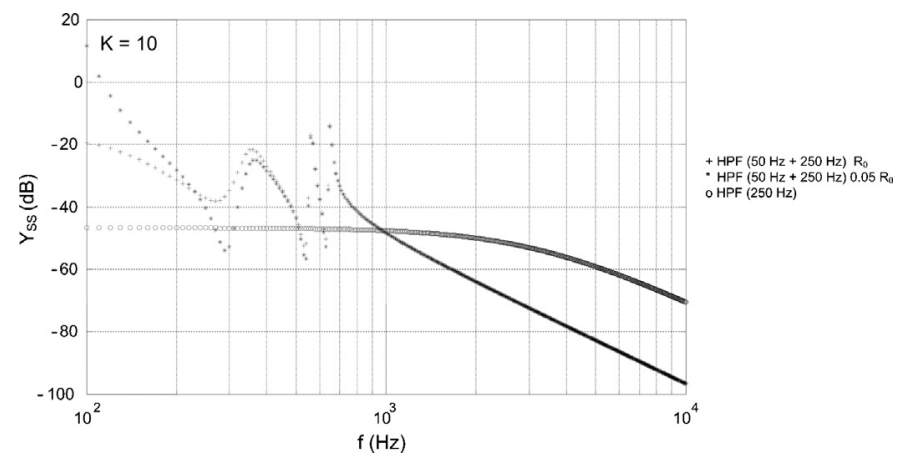

Fig. 6. Comparison of $Y_{\mathrm{SS}}=i_{\mathrm{S}} / u_{\mathrm{S}}$ for HPF with the series connection of only one passive $L-C$ resonant circuit $\left(250 \mathrm{~Hz}, Z_{0} \rightarrow \infty\right)$ to that for the proposed HPF with the split passive part (here for two different $R_{0}$ values).

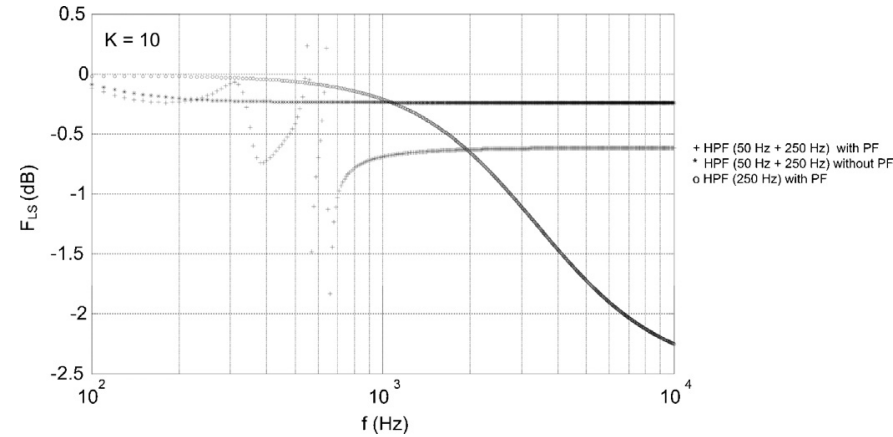

Fig. 7. Comparison of $F_{\mathrm{LS}}=u_{\mathrm{L}} / u_{\mathrm{S}}$ for the HPF with series connection of only one passive $L-C$ resonant circuit $\left(250 \mathrm{~Hz}, Z_{0} \rightarrow \infty\right)$ to that for the proposed HPF with the split passive part (either with or without PF).

for only passive parts in function, while the grid inductance changes are insignificant and the harmonic current mitigation is more effective for the full HPF. Thus, the proposed HPF topology exhibits a very low sensitivity to the changes in the grid inductance $L_{S}$.

Fig. 4 compares the frequency characteristics $F_{\mathrm{SL}}=i_{\mathrm{S}} / i_{\mathrm{L}}$ for the HPF with the series connection of only one passive $L-C$ resonant circuit $\left(250 \mathrm{~Hz}, Z_{0} \rightarrow \infty\right)$ with that for the proposed HPF with the split passive part as shown in Fig. 2. The well-known HPF topology provides a better performance up to the frequency about $300 \mathrm{~Hz}$ $(K=10)$ but for higher frequencies the proposed HPF yields much higher attenuation of the harmonics in the grid current than the simpler HPF topology.

Fig. 5 compares the frequency characteristics $F_{\mathrm{AFL}}=i_{\mathrm{AF}} / i_{\mathrm{L}}$ for the same two HPF options as in Fig. 4. It is evident that the proposed HPF with the split passive part needs a lower magnitude of the current $i_{\mathrm{AF}}$ generated by the converter than the topology without $Z_{0}$ for the same load current $i_{\mathrm{L}}$ value in the frequency range $200-1500 \mathrm{~Hz}$. The frequency characteristic $F_{\mathrm{AFL}}=i_{\mathrm{AF}} / i_{\mathrm{L}}$ for the simpler topology without $Z_{0}$ is becoming better for higher frequencies but this topology's filtration effectiveness above $1500 \mathrm{~Hz}$ is very low according to Fig. 4 . Thus, in terms of the harmonic load current $i_{S}$ attenuation with a reasonable converter current value $i_{\mathrm{AF}}$, the proposed HPF topology is more effective than the conventional one (with only one passive $L-C$ resonant circuit, $Z_{0} \rightarrow \infty$ ) with the exception of the lowest frequencies where the proposed HPF is not as good as the conventional HPF strategy. Therefore, closer attention must be paid to the process how the load current components below $200 \mathrm{~Hz}$ (especially that with the fundamental frequency) are filtered out in the process of obtaining the converter reference harmonic current $i_{\mathrm{AF}}=-K \cdot i_{\mathrm{S}}$ in order to avoid generating converter currents that are too high in this frequency range with the small filtration effect.

Fig. 6 shows the frequency characteristics $Y_{S S}=i_{S} / u_{S}$ for the HPF with the series connection of only one passive $L-C$ resonant circuit $\left(250 \mathrm{~Hz}, \mathrm{Z}_{0} \rightarrow \infty\right)$ to that for the proposed HPF with the split passive part (here for two $R_{0}$ values: (a) declared in the Appendix $\mathrm{A}$, and (b) lowered to only $5 \%$ of that value). We can see that the proposed HPF yields higher attenuation of the harmonics in the grid current induced by the grid voltage harmonics for higher frequencies than the well-known, simpler HPF topology. However, a real danger exists that a grid voltage component with a very low frequency can produce a remarkable respective grid current component, especially for decreased $R_{0}$ values.

Fig. 7 compares the frequency characteristics $F_{\mathrm{LS}}=u_{\mathrm{L}} / u_{\mathrm{S}}$ for the HPF with the series connection of only one passive $L-C$ resonant circuit $\left(250 \mathrm{~Hz}, Z_{0} \rightarrow \infty\right)$ to that for the proposed HPF with the split passive part (either with or without PF). Contrary to the frequency characteristic $Y_{\mathrm{SS}}=i_{\mathrm{S}} / u_{\mathrm{S}}$ (Fig. 6 ), the simplified HPF version (with only one $L-C$ resonant circuit tuned to $250 \mathrm{~Hz}$ ) provides better results here than those for the proposed HPF topology in the higher 
frequency range. Although the effectiveness of the proposed HPF with the parallel passive branches tuned to the 7th, 11th and 13th harmonics is better up to about $2000 \mathrm{~Hz}$, some resonance peaks can occur here due to the presence of these PFs tuned to some harmonic frequencies. But generally speaking, the attenuation of the harmonic voltage at the point of coupling for both the options is very low. A general rule for APFs and HPFs connected in parallel to the load states that the load voltage endurance vis-à-vis the harmonic grid voltage is very poor. This rule is confirmed according to Fig. 7.

As for the fundamental frequency, the substantial advantage of the proposed HPF topology over that of the stand-alone APF is that the active part (converter) is connected to a much lower voltage in comparison with the full grid voltage in case of the stand-alone APF. For example, it was found that this voltage is only $11.4 \%$ of the fundamental frequency full grid voltage for the parameters declared by the table in the Appendix A.

\section{Industrial system and measurement}

The measurements of the harmonic emission and the consumed reactive power were performed in an industrial plant in the Czech Republic where many plastic waste extruder drives and recycling machines are in operation. This industrial plant was chosen because
Table 1

Loads overview in the plant.

\begin{tabular}{lcc}
\hline Load type & $\begin{array}{l}\text { Total load powers } \\
S_{\mathrm{A}}(\mathrm{kVA})\end{array}$ & $\begin{array}{l}\text { Powers of loads } \\
\text { producing } \\
\text { harmonics } S_{\mathrm{OS}} \\
(\mathrm{kVA})\end{array}$ \\
\hline IM connected directly to the grid & 93 & - \\
IM supplied via frequency converters & 365 & 365 \\
DC motors supplied via rectifiers & 42 & 42 \\
Heating & 52 & - \\
Fluorescent lighting & 15 & 15 \\
Total plant input power & 567 & 422 \\
\hline
\end{tabular}

appliances and non-linear loads broad portfolio producing harmonics and influencing power quality are installed there. The loads overview in the plant is presented in Table 1.

An example of the performance parameters for different loads in some operation modes measured in the plant is presented in Table 2.

The different loads currents composition in the plant is visualized in Fig. 8.

The voltage and current responses and their harmonic spectra were measured in the industrial plant under different conditions (without compensation, with traditional central passive compen-

Table 2

Example of loads performance parameters in the plant.

\begin{tabular}{|c|c|c|c|c|c|c|c|c|}
\hline Load type & $U_{\mathrm{L}}(\mathrm{V})$ & $I_{\mathrm{L}}(\mathrm{A})$ & $P_{\mathrm{L}}(\mathrm{kW})$ & $Q_{\mathrm{L}}(\mathrm{kVAr})$ & $S_{\mathrm{L}}(\mathrm{kVA})$ & $T H D_{\mathrm{UL}}(\%)$ & $T H D_{\mathrm{IL}}(\%)$ & $\cos \phi_{\mathrm{L}}$ \\
\hline IM supplied via frequency converters & 225.6 & 114.0 & 74.8 & 16.7 & 76.6 & 2.57 & 45.60 & 0.976 \\
\hline IM connected directly to the grid & 225.6 & 231.4 & 56.7 & 94.5 & 110.3 & 2.57 & 0.48 & 0.515 \\
\hline Heating & 225.6 & 42.3 & 28.4 & 0.0 & 28.4 & 2.57 & 2.57 & 1.000 \\
\hline Fluorescent lighting & 225.6 & 0.0 & 0.0 & 0.0 & 0.0 & 2.57 & 100.00 & 1.000 \\
\hline DC motors supplied via rectifiers & 225.6 & 11.7 & 3.6 & 7.0 & 7.9 & 2.57 & 34.97 & 0.458 \\
\hline Total plant & 225.6 & 300.4 & 163.9 & 118.2 & 202.1 & 2.57 & 17.03 & 0.811 \\
\hline
\end{tabular}
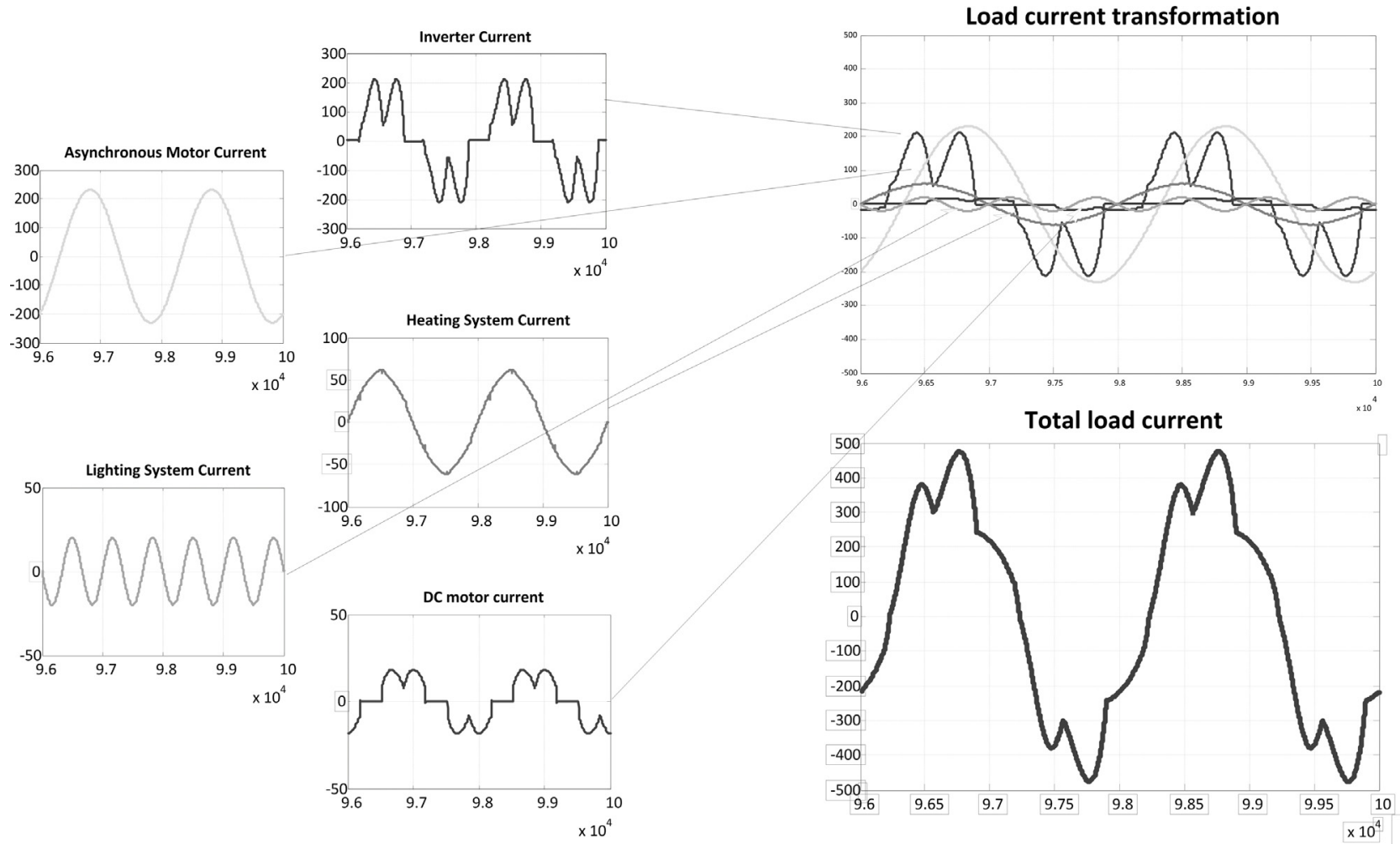

Fig. 8. Load current waveform composition (for maximum machine loads) in the plant. 


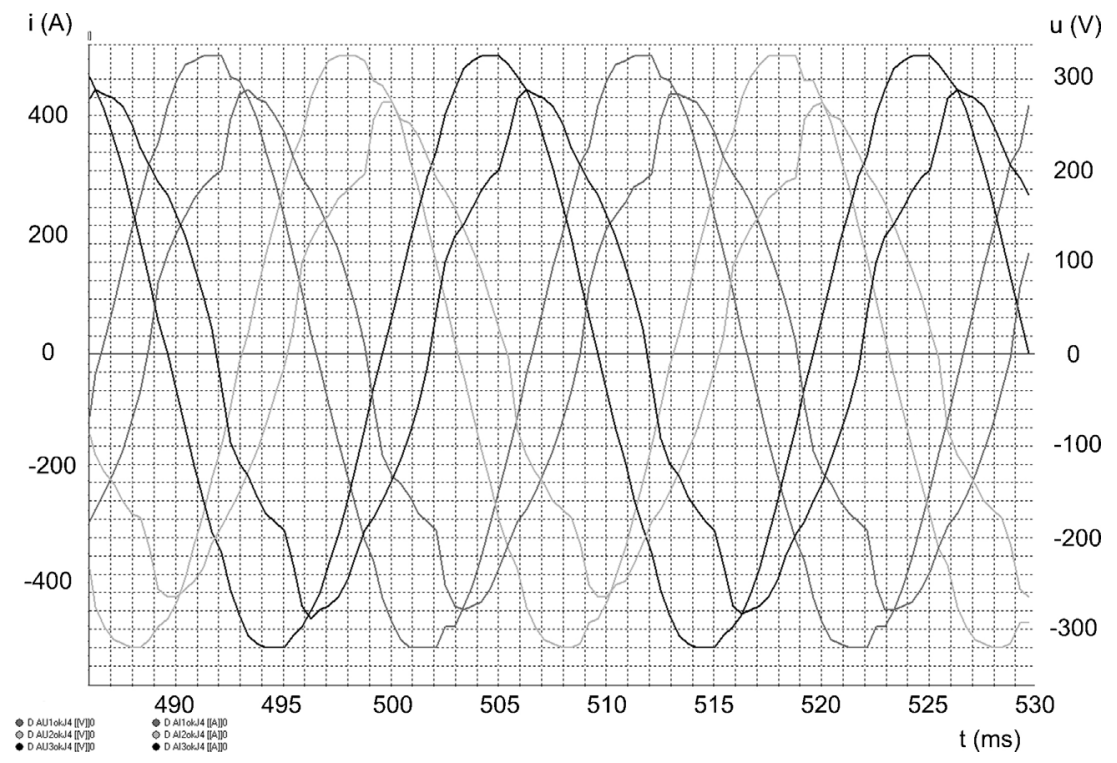

Fig. 9. Voltage and current waveforms measured in the plant input point without any reactive power compensation (for maximum machine loads).

sation) and compared with the results obtained by the simulation carried out in the Matlab/Simulink environment for the same conditions. In the next chapter, these results are compared with the data obtained when the aforementioned compared HPF topologies are implemented into the plant model.

Fig. 9 shows voltage and current waveforms measured in the plant input point without any reactive power compensation (for maximum machine loads). The power factor without any reactive power compensation reaches the value 0.81 .

Fig. 10 shows similar responses if the classical central reactive power compensation using capacitor banks with 5, 10, 15, 25 and $60 \mathrm{kVAr}$ steps controlled by a reactive power controller (with the reference power factor $=0.97$ ) was applied. The current harmonic spectrum is obviously worse than that in Fig. 9 at the expense of the better power factor.

This current harmonic spectrum without any reactive power compensation measured in the plant input point is in Fig. 11.

\section{Simulation results}

The plant model with all loads was established in the first stage. The load models and their parameters were tuned in order to obtain the current waveforms and the main power quality indices provided by the simulation as close as possible to the measured ones. It is clear that we cannot expect absolute conformity due to the presence of many different loads in the plant (see Table 1). Nevertheless, a good agreement is necessary so that we can rely on the simulation results obtained after the HPF topologies implementation into the plant model. The HPFs and PFs parameters are summarized in the table in the Appendix A.

The plant system was modeled in the Matlab/Simulink environment by using the individual drives and loads models from the SimPowerSystems library. The drives and other loads were grouped according to their load current responses. An IM (induction machine) used as the extruder drive and three IMs for

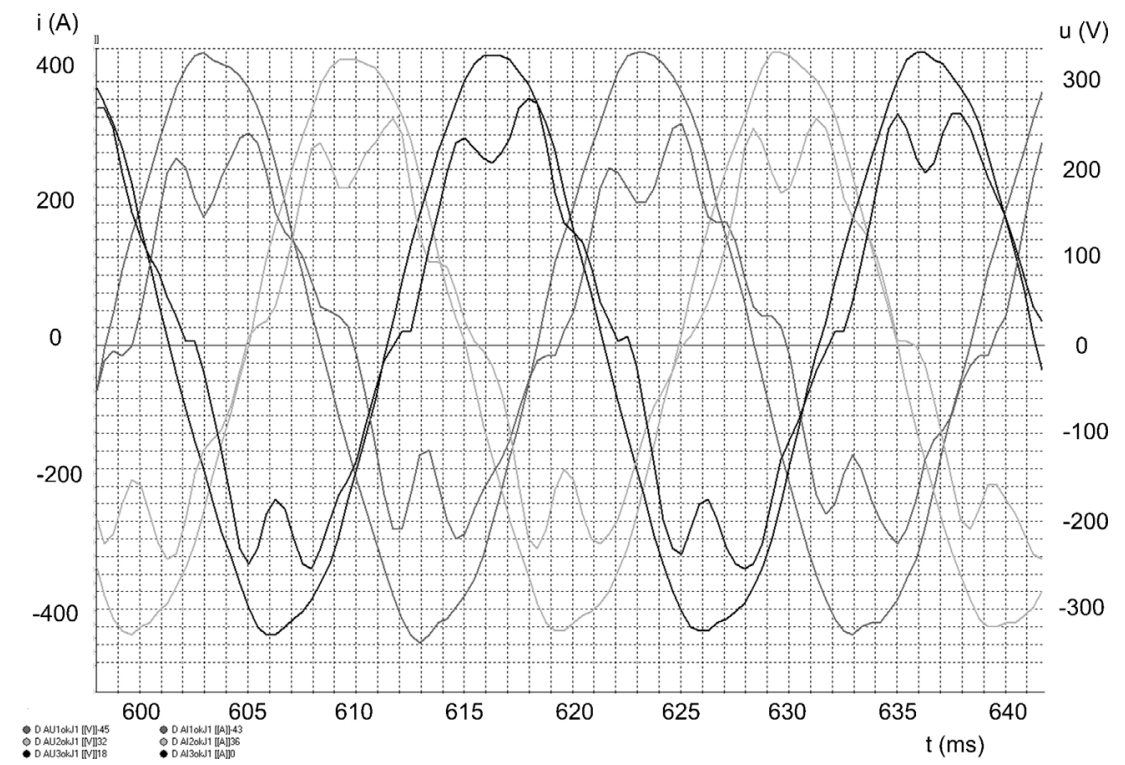

Fig. 10. Voltage and current waveforms measured in the plant input point with classical central reactive power compensation using capacitor banks with $5,10,15,25$ and $60 \mathrm{kVAr}$ steps (here the $25 \mathrm{kVAr}$ step was set by the reactive power controller). 


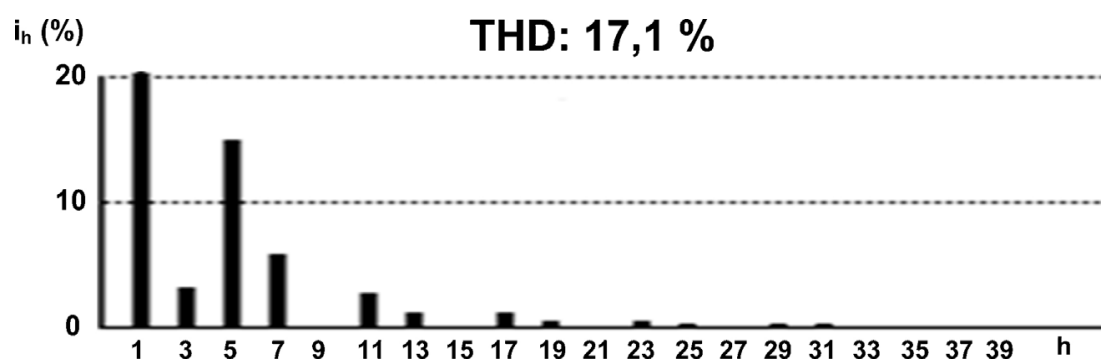

Fig. 11. Current harmonic spectrum measured at the plant input point without any reactive power compensation.
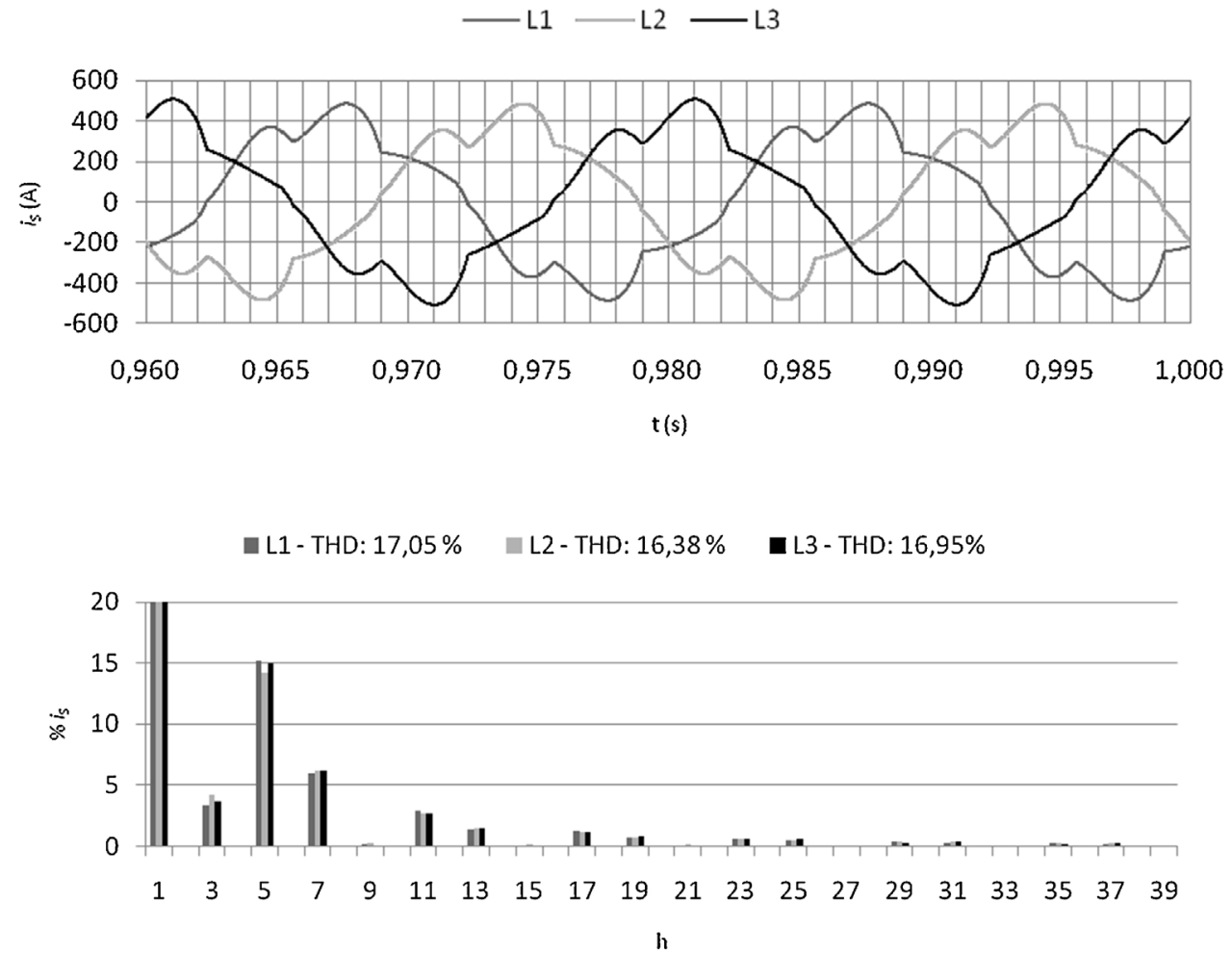

Fig. 12. Phase current waveforms and harmonic spectra in the plant input point without any reactive power compensation.

driving extruder belts were fed from inverters and modeled as field-oriented controlled IM drives. The DC drives fed from phasecontrolled rectifiers were modeled as two-quadrant, three-phase rectifier DC drives. The heating consumption was modeled as a set of resistors, while the fluorescent lighting by means of an AC threephase current source with the frequency $150 \mathrm{~Hz}$. The main problem was that measured current and power responses were extensively fluctuating due to the main extruder changing load, which made the comparison with the simulation results very problematic and laborious because the mechanical extruder model in and of itself was not included into the simulation and only electric system steady states were simulated.

Source current with HPF $i_{\mathrm{s}}(\mathrm{A})$ - type 2

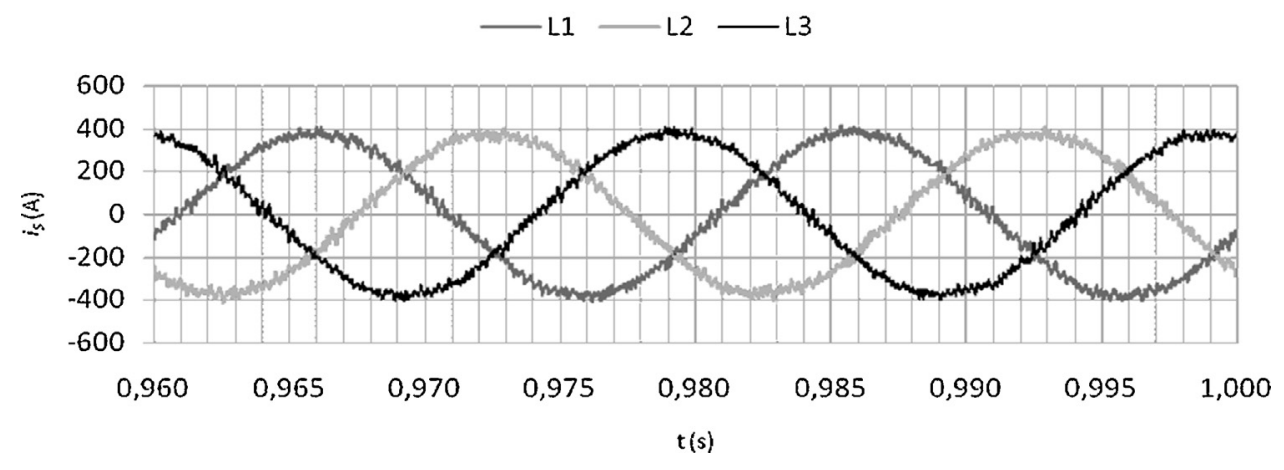

Fig. 13. Simulated three phase grid currents when the proposed HPF (=type 2 ) was used (full load). 

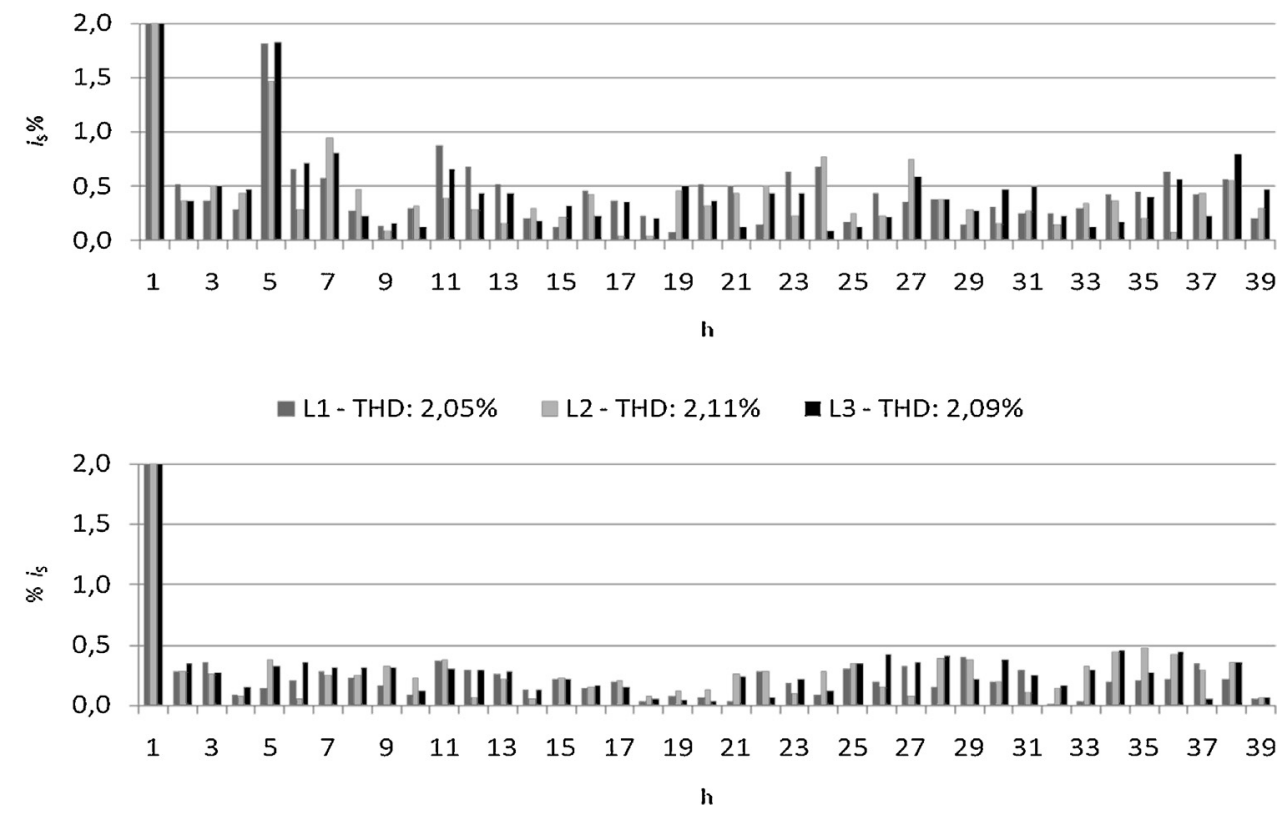

Fig. 14. Grid current $i_{\mathrm{S}}$ harmonic spectrum for the HPF without $Z_{0}$ impedance (top) and the proposed HPF (bottom).

The phase currents waveforms and harmonic spectra in the plant input point without any reactive power compensation are in Fig. 12.

Comparing the waveforms and harmonic spectra in Fig. 12 with those obtained by the measurement in the plant input point under the same conditions (Figs. 9 and 11) we can see a relatively good agreement, especially in current harmonic spectra and THD. Some differences in the measured and simulated waveforms exist due to the complexity of the plant system and difficulties to catch and compare exactly the same steady state as that which was simulated. The reason is that fluctuating mechanical processes were not simulated. For example, the measured phase currents peak values shown in Fig. 9 are between 425 and 445 A, while those obtained by simulation in Fig. 12 are between 490 and 510 A. Nevertheless, with respect to the comparison of many experimental and simulation data similar to those presented in Figs. 9 and 12, we can expect that the system model with the HPF models included will provide us with results accurate enough to compare correctly the
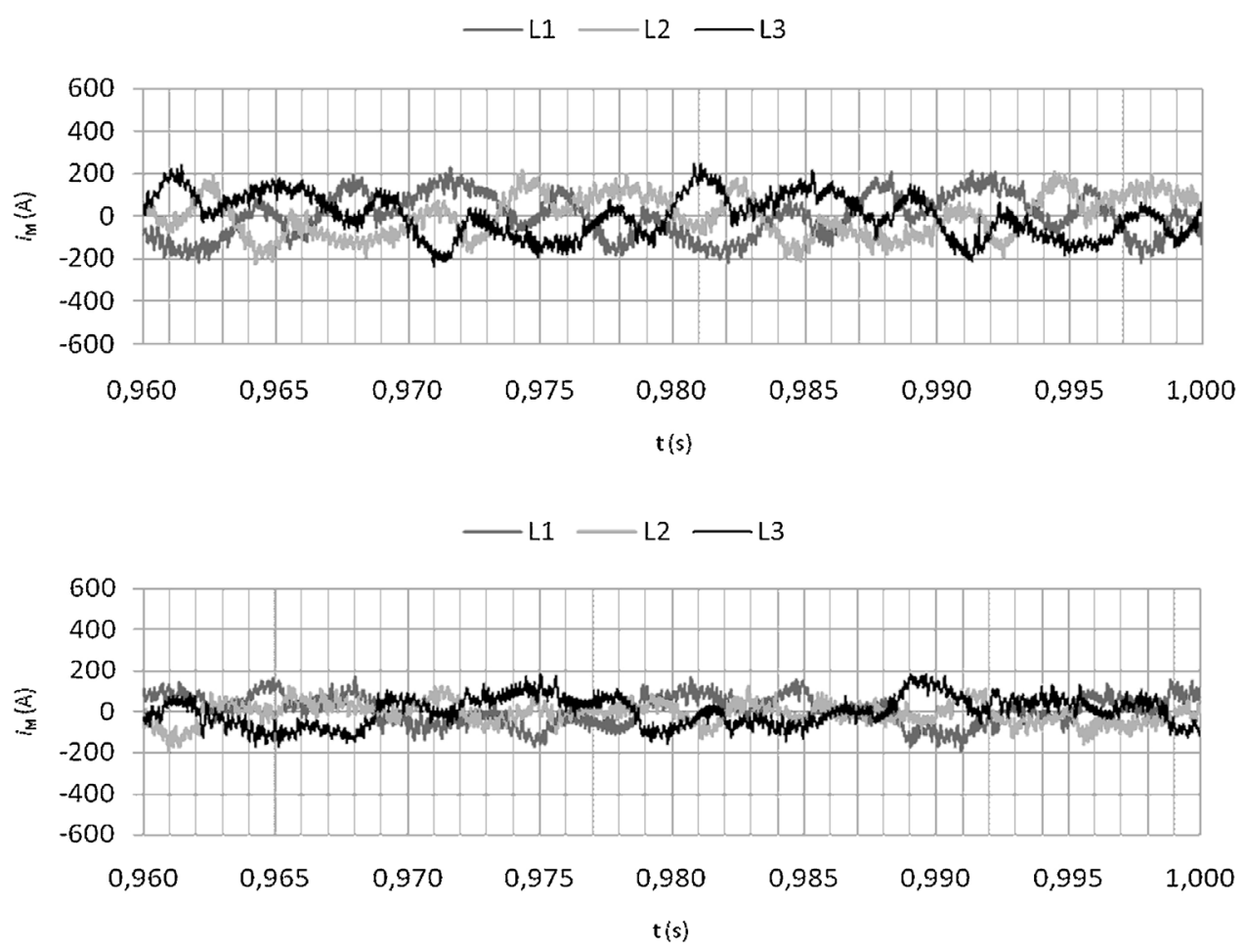

Fig. 15. Electronic power converter current $i_{\mathrm{M}}$ for the HPF without $Z_{0}$ impedance (top) and the proposed HPF (bottom). 


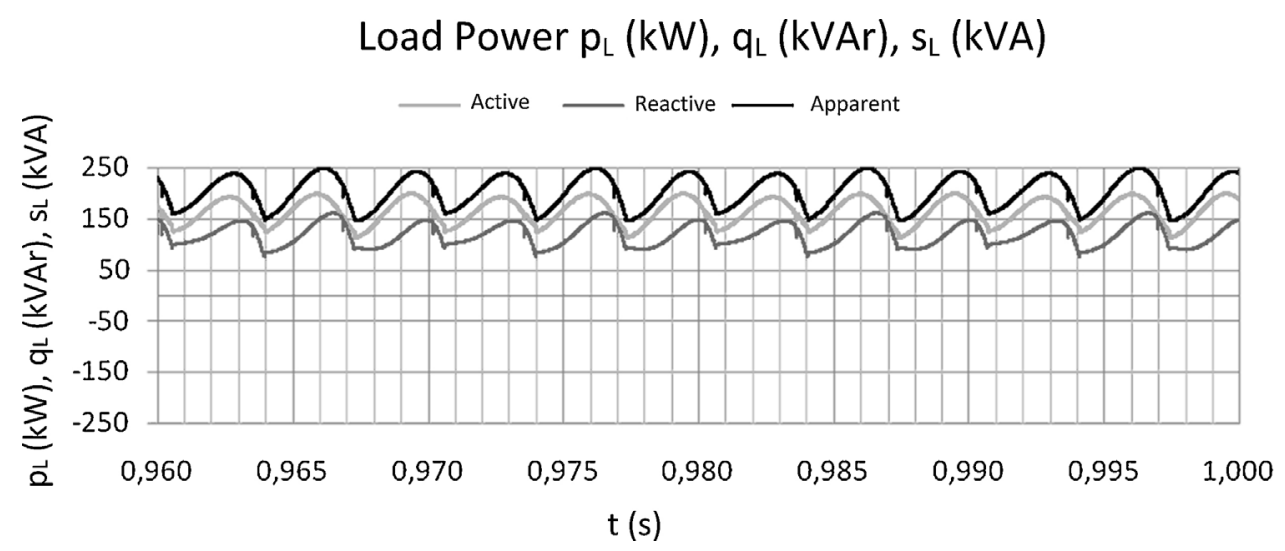

Fig. 16. Instantaneous active, reactive and apparent power of the plant load.

effectiveness of the compensation strategies analyzed, especially in terms of the current harmonic spectra and respective THDs.

Fig. 13 shows the simulated three-phase grid currents when the proposed HPF (=type 2 ) was used (full load).

Figs. 14 and 15 are presented to enable comparing both the HPF topologies (without and with the branch with $Z_{0}$ impedance) in terms of grid current harmonic spectra and the waveform of the compensating current generated by the electronic power converter (the lower, the better). Again, these figures confirm the superiority of the proposed HPF over the classical topology without the branch with $Z_{0}$ impedance.

Fig. 16 shows the instantaneous active, reactive and apparent power of the plant load.
Figs. 17 and 18 show the instantaneous active, reactive and apparent power injected by the electronic power converter and exchanged with the grid.

Fig. 17 shows the powers for the HPF without $Z_{0}$ (=type 1 ), while Fig. 18 shows those for the proposed HPF (=type 2 ) in operation. If we compare Fig. 17 (top) and Fig. 18 (top) we can see the power fluctuations are visibly lower in the case of the proposed HPF than those for the HPF without $Z_{0}$ impedance, although approximately the same compensation level is attained (see Fig. 17 (bottom), 18 (bottom)).

Table 3 compares calculated average RMS values of $U_{\mathrm{L}}, I_{\mathrm{L}}$, $I_{\mathrm{M}}$ (converter current), THD and PF (demanded $\mathrm{PF}=0.97$ ) for the uncompensated industrial plant and for different compensation
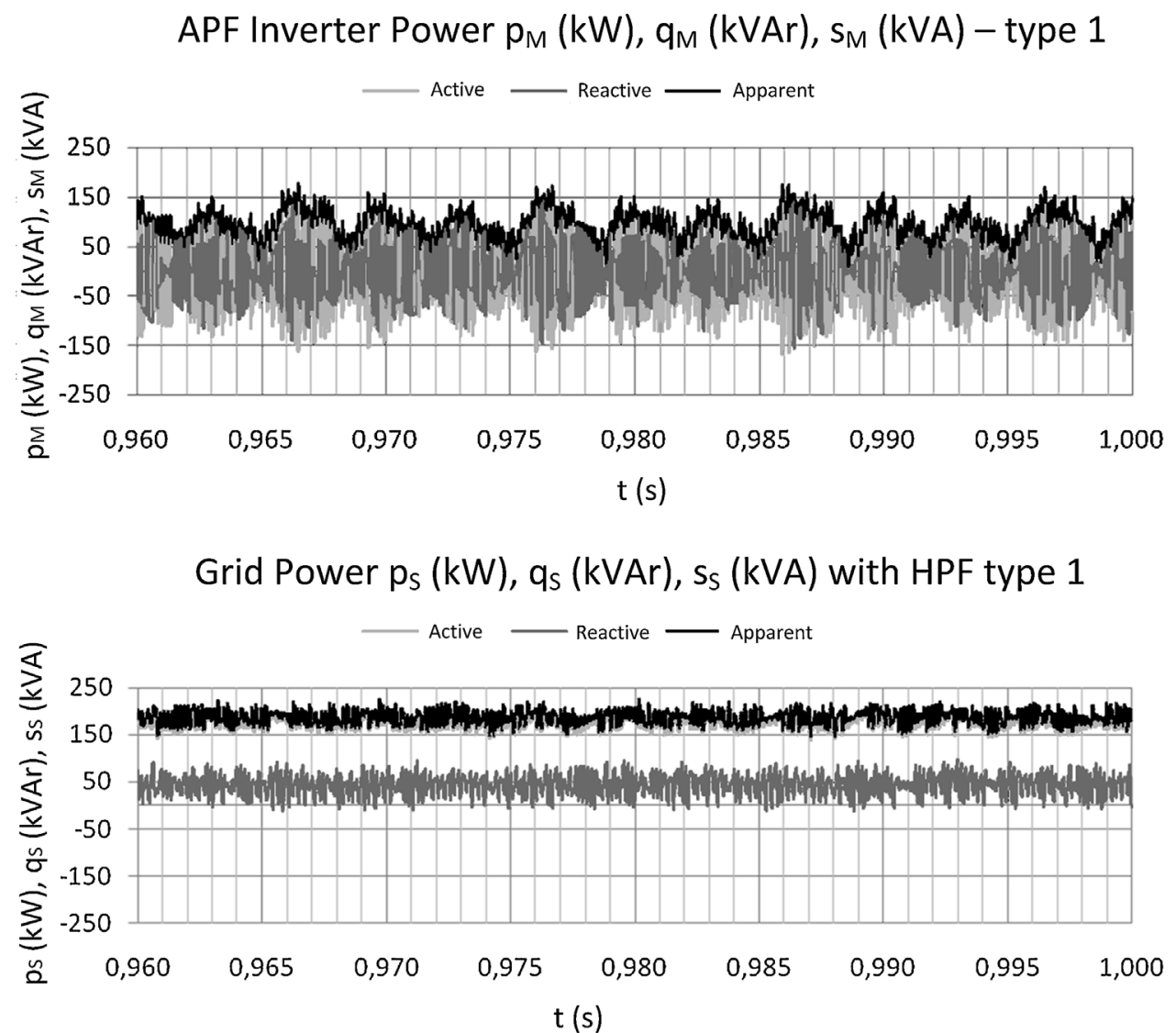

Fig. 17. Instantaneous active, reactive and apparent power injected by the electronic power converter (top) and exchanged with the grid (bottom) if $H P F$ without $Z_{0}$ impedance (=type 1) is used. 

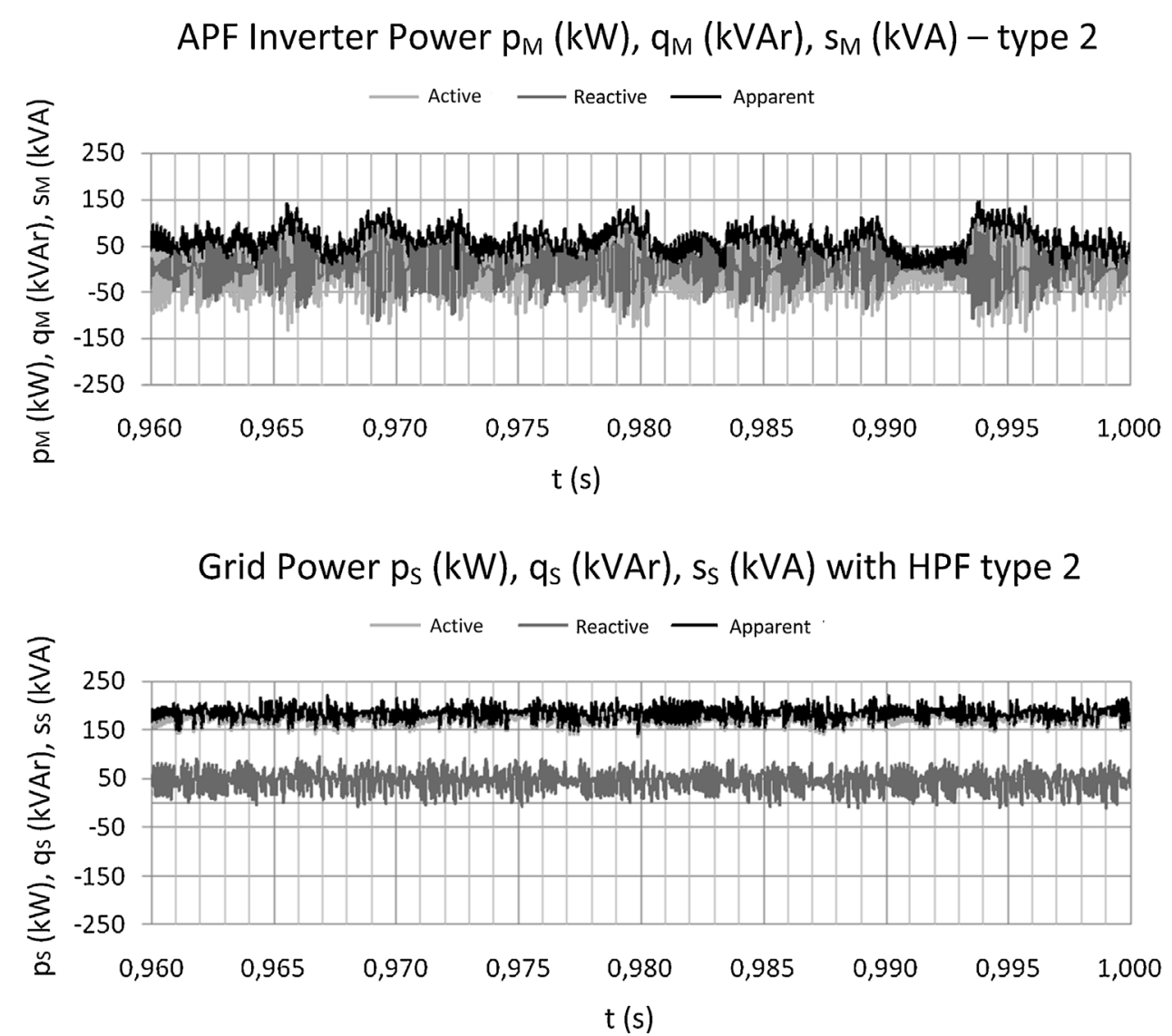

Fig. 18. Instantaneous active, reactive and apparent power injected by the electronic power converter (top) and exchanged with the grid (bottom) for the proposed HPF (=type 2).

Table 3

Calculated average RMS values of $U_{\mathrm{L}}, I_{\mathrm{L}}, I_{\mathrm{M}}, T H D$ and power factor (demanded power factor $=0.97$ ).

\begin{tabular}{|c|c|c|c|c|c|c|}
\hline Compensation type & $U_{\mathrm{L}}(\mathrm{V})$ & $I_{\mathrm{L}}(\mathrm{A})$ & $I_{\mathrm{M}}(\mathrm{A})$ & $T H D_{\text {US }}(\%)$ & $T H D_{\mathrm{IS}}(\%)$ & Power factor \\
\hline Without compensation & 225 & 304 & - & 2.56 & 16.8 & 0.81 \\
\hline With classical reactive power compensation & 228 & 301 & - & 4.66 & 28.3 & 0.97 \\
\hline HPF without $Z_{0}$ & 227 & 301 & 98.5 & 0.45 & 3.04 & 0.97 \\
\hline Proposed HPF & 227 & 304 & 71.5 & 0.38 & 2.08 & 0.97 \\
\hline
\end{tabular}

types. Comparing $T H D_{\mathrm{US}}, T H D_{\mathrm{IS}}$ and $I_{\mathrm{M}}$ for both HPF topologies (without and with the branch with $Z_{0}$ impedance), we can see quantitative differences between these two topologies.

Generally we can come to the conclusion that the proposed HPF topology with a split passive part compensates for the load current harmonics effectively with low harmonic currents generated by the $\mathrm{HPF}$ converter. The fundamental frequency voltage at the converter terminals is much lower than the voltage at the PCC at the same time.

\section{Conclusions}

The HPF topology with the split passive part was presented and analyzed. The passive part impedance is divided into two individual parts tuned to $50 \mathrm{~Hz}$ and $250 \mathrm{~Hz}$.

The developed HPF behavior and properties were compared with those for the HPF without $Z_{0}$ and for the passive reactive power compensation by a simulation carried out in the Matlab/Simulink environment. The obtained simulation results were in agreement with those obtained by a theoretical analysis done in the frequency domain. The results confirm the superiority of the new HPF over the other considered compensation topologies.
The voltage and current responses and their harmonic spectra were also measured in a real industrial plant under different conditions (without compensation, with classical central reactive power compensation) and compared to those obtained by the developed plant system simulation model to verify this model's accuracy. The new HPF topology and control strategy were implemented into the industrial system model to test its ability and expected superiorities over standard PF and HPF topologies to filter out undesired harmonic currents.

The new topology is more effective to mitigate non-linear load harmonic currents than the conventional HPF without $Z_{0}$. The fundamental frequency voltage at the electronic power converter terminals is much lower than the voltage at the PCC at the same time. Nevertheless, the proposed HPF topology, as with all parallel APFs and HPFs, cannot be used for the effective mitigation of the grid harmonic voltage infiltration into the voltage at the PCC. The proposed topology cannot be recommended for systems in which low-frequency grid voltage components may be expected because they could induce unacceptable respective grid current components.

Although the proposed topology appears to be promising, especially for medium voltage applications, further research should be devoted to the problem of how to prevent the converter 
Table A.1

HPF and PFs parameters.

\begin{tabular}{|c|c|c|c|c|c|}
\hline Grid & PF1 & PF5 & PF7 & PF11 & PF13 \\
\hline$R_{\mathrm{S}}=0.0113 \Omega$ & $R_{\mathrm{PF} 1}=R_{0}=0.364 \Omega$ & $C_{\mathrm{PF} 5}=1 /\left(1 / C_{0}+1 / C_{1}\right)$ & $R_{\mathrm{PF7}}=0.02 \Omega$ & $R_{\mathrm{PF} 11}=0.17 \Omega$ & $R_{\mathrm{PF} 13}=0.17 \Omega$ \\
\hline$L_{\mathrm{S}}=0.0493 \mathrm{mH}$ & $\begin{array}{l}L_{\mathrm{PF} 1}=L_{0}=0.456 \mathrm{mH} \\
C_{\mathrm{PF} 1}=C_{0}=22.22 \mathrm{mF}\end{array}$ & $C_{1}=1 \mathrm{mF}$ & $\begin{array}{l}L_{\mathrm{PF7}}=0.405 \mathrm{mH} \\
C_{\mathrm{PF7}}=0.51 \mathrm{mF}\end{array}$ & $\begin{array}{l}L_{\mathrm{PF} 11}=2 \mathrm{mH} \\
C_{\mathrm{PF} 11}=40 \mu \mathrm{F}\end{array}$ & $\begin{array}{l}L_{\mathrm{PF} 13}=2 \mathrm{mH} \\
C_{\mathrm{PF} 13}=30 \mu \mathrm{F}\end{array}$ \\
\hline
\end{tabular}

from generating a residual fundamental frequency current which could flow through the passive part PF1 $\left(L_{0}, C_{0}\right)$ with very low resistance.

\section{Acknowledgments}

The financial support of the Grant Agency of the Academy of Sciences of the Czech Republic (project no. IAA200760703), Institutional Research Plan Z20570509 of the Institute of Thermomechanics of the ASCR, v.v.i., and of the Grant Agency of the Czech Technical University in Prague (grant No. SGS12/139/OHK3/2T/13) Ministry of Education, Youth, and Sports (Research Plan MSM 6840770017 of the Czech Technical University) are highly acknowledged.

\section{Appendix A.}

The HPF passive part contains three main elements $L_{0}, C_{0}$ and $C_{1}$. The PF1 $\left(L_{0}, C_{0}\right)$ is tuned to $50 \mathrm{~Hz}$, the PF5 $\left(L_{0}, C_{\mathrm{PF} 5}=1 /\left(1 / C_{0}+1 / C_{1}\right)\right)$ to $250 \mathrm{~Hz}$. Thus two degrees of freedom are used for tuning the PF1, PF5 and the remaining third one is used to define the reactive power we want to inject (together with the PF7, PF11, PF13) into the point of coupling to get the desired grid power factor (Table A.1).

\section{References}

[1] L. Gyugyi, E.C. Strycula, Active AC power filters, in: Proceedings of IEEE/Ind. App. Society Annual Meeting, 1976, pp. 529-535.

[2] N. Mohan, H.A. Peterson, W.F. Long, G.R. Dreifuerst, J.J. Vithayathil, Active filters for ACharmonic suppression, in: Presented at the IEEEPower Engineering Society Winter Meeting, 1977, paper A77026-8.

[3] H. Akagi, New trends in active filters for power conditioning, IEEE Trans. IA-32 (1996) 1.312-1.322.

[4] F. Peng, H. Akagi, A. Nabae, A new approach to harmonic compensation in power system - a combined system of shunt passive and series active filters, IEEE Trans. Ind. Appl. 26 (6) (1990, November/December) 983-990.

[5] F.P. Venter, A. Zuccato, L. Malesani, A power filter for harmonic isolation of non-linear loads, Electron (1994, July) 10-11.

[6] J. Hafner, M. Aredes, K. Heumann, Utilization of a small-rated shunt active power filter combined with a conventional passive filter for large power systems, in: Proceedings of PEMC'94, Warsaw, Poland, 1994, pp. 190-195.

[7] M. Kowalski, R. Strzelecki, The hybrid filter of network current harmonics with the compensation of the reactive component, in: Proceedings of PEMC'94, Warsaw, Poland, 1994, pp. 219-224.

[8] H. Pouliquen, E. Bettega, M. Wang., A new control strategy of combined system of series active and shunt passive filters for minimizing passive filter number, in: EPE'95, Sevilla, Spain, 1995, pp. 1.135-1.139.

[9] A.A. Bayod Rujula, M. Sanz Badia, A new approach to harmonic compensation with hybrid active filters, in: Proceedings of EPE'95, Sevilla, Spain, 1995, pp. 1.925-1.928.

[10] M. Rastagi, N. Mohan, A. Edris, Hybrid-active filtering of harmonic currents in power system, IEEE Trans. Power Del. 10 (4) (1995, October) 1994-2000.

[11] A.A. Bayod Rujula, J. Sallán Arasanz, M. Sanz Badía, A. Llombart Estopiňán, Searching for the better topology and control strategy in hybrid power filters, in: Proceedings of EPE'97, Trondheim, Norway, 1997, pp. 4.825-4.829.

[12] S. Bhattachaya, P.-T. Cheng, D.M. Divan, Hybrid solutions for improving passive filter performance in high power applications, IEEE Trans. Ind. Appl. 33 (3) (1997, May/June) 732-747.
[13] H.-L. Jou, J.-C. Wu, K.-D. Wu, Parallel operation of passive power filter and hybrid power filter for harmonic suppression, Proc. Inst. Elect. Eng. Gen. Transm. Distrib. 148 (1) (2001, January) 8-14.

[14] S.M. Rafiei, H.A. Toliyat, R. Ghazi, T. Gopalarathnam, An optimal and flexible control strategy for active filtering and power factor correction under nonsinusoidal line voltages, IEEE Trans. Power Del. 16 (2) (2001, April) 297-304.

[15] B.-R. Lin, T.-Y. Yang, Implementation of active power filter with asymmetrical inverter legs for harmonic and reactive power compensation, Electr. Power Syst. Res. 73 (2) (2005, February) 227-237, http://dx.doi.org/10.1016/j.epsr.2004.08.007.

[16] B. Singh, V.Verma, Selective compensation of power-quality problems through active power filter by current decomposition, IEEE Trans. Power Del. 23 (2) (2008, April) 792-799.

[17] H. Fujita, H. Agaki, The unified power quality conditioner of series and shuntactive filters, IEEE Trans. Power Electron. 13 (2) (1998, March) 315-322.

[18] K.J.P. Macken, K.M.H.A. De Brabandere, I.J.L. Dnesen, R.J.M. Belmans, Evaluation of control algorithms for shunt active tillers under unbalanced and nonsinusoidal conditions, in: Presented at the IEEE Porta Power Teck Conference, Porto, Portugal, 2001, September 10-13.

[19] M. Kale, E. Ozdemir, Harmonic and reactive power compensation with shunt active power filter under non-ideal mains voltage, Electr. Power Syst. Res. 74 (2005) 363-370, http://dx.doi.org/10.1016/j.epsr.2004.10.014.

[20] H.-L Jou, J.Ch. Wu, K.-D. Wu, M.-S. Huang, Control method for parallelconnected hybrid filters, Electr. Power Syst. Res. 76 (1-3) (2005, September) 121-126, http://dx.doi.org/10.1016/j.epsr.2005.05.003.

[21] G.W. Chang, A new approach for optimal shunt active power filter control with considering alternative performance indices, IEEE Trans. Power Del. 21 (1) (2006, January) 406-413.

[22] S. George, V. Agarwal, A DSP based optimal algorithm for shunt active filter under non-sinusoidal supply and unbalanced load conditions, IEEE Trans. Power Electron. 22 (2) (2007, March) 593-601.

[23] M. Routimo, M. Salo, H. Tuusa, Comparison of voltage-source and currentsource shunt active power filters, IEEE Trans. Power Electron. 22 (2) (2007, March) 636-643.

[24] J.-Ch. Wu, K.-D. Wu, H.-L. Jou, S.-T. Xiao, Diode-clamped multi-level converter with a zero-sequence current loop for three-phase three-wire hybrid filter, Electr. Power Syst. Res. 81 (2) (2011, February) 263-270, http://dx.doi.org/10.1016/j.epsr.2010.09.001.

[25] J.W. Dixon, G. Venegas, L.A. Morán, A series active power filter based on a sinusoidal current-controlled voltage-source inverter, IEEE Trans. IE-44 (1997) 612-620.

[26] Ch. Madtharad, S. Premrudeepreechacharn, Active power filter for three-phase four-wire electric systems using neural network, Electr. Power Syst. Res. 60 (3) (2002, January 28) 179-192, http://dx.doi.org/10.1016/S0378-7796(01)00185-7.

[27] D. Sreenivasarao, P. Agarwal, B. Das, Neutral current compensation in threephase, four-wire systems: a review, Electr. Power Syst. Res. 86 (2012, May) 170-180, http://dx.doi.org/10.1016/j.epsr.2011.12.014.

[28] A. Garces, M. Molinas, P. Rodriguez, A generalized compensation theory for active filters based on mathematical optimization in ABC frame, Electr. Power Syst. Res. 90 (2012, September) 1-10, http://dx.doi.org/10.1016/j.epsr.2012.03.011.

[29] F.P. Venter, J.D. van Wyk, J.J. Schoemann, A study of the effectivity of reducing the energy storage element in dynamic filters for compensation of non-active power, Trans. SA IEE (1994) 43-50.

[30] G. Vaupel, Wide-band filter with actively reduced losses for power systems, in: Proceedings of EPE'95, Sevilla, Spain, 1995, pp. 1. 892-1.897.

[31] J.-Ch. Wu, H.-L. Jou, K.-D. Wu, H.-H. Hsiao, Three-phase four-wire hybrid filter using a smaller converter, Electr. Power Syst. Res. 87 (2012, June) 13-21, http://dx.doi.org/10.1016/j.epsr.2012.01.001.

[32] S. Srianthumrong, H. Akagi, A medium-voltage transformerless AC/DC power conversion system consisting of a diode rectifier and a shunt hybrid filter, IEEE Trans. IA-39 3 (2003) 874-882.

[33] Z. Shuai, A. Luo, W. Zhu, R. Fan, K. Zhou, Study on a novel hybrid active power filter applied to a high-voltage grid, IEEE Trans. PD 24 (4) (2009, October) 2344-2352. 